\title{
Incidence of childhood overweight and obesity and its association with weight- related attitudes and behaviors in China: a national longitudinal study
}

\author{
Li Cai ${ }^{1+}$, Meixia Dai ${ }^{1 \dagger}$, Lizi Lin², Wenhan Yang ${ }^{1}$, Yajun Chen ${ }^{1}$, Jun Ma ${ }^{2^{*}}$ and Jin Jing ${ }^{1 *}$
}

\begin{abstract}
Background: Childhood obesity is a major public health challenge. We aimed to investigate the incidence of overweight/obesity among Chinese children; and prospectively examine the associations of weight-change intention with risk of overweight/obesity and behavioral changes in initially normal-weight children.

Methods: A national sample of 21,796 children aged 6-17 years were investigated in September 2013 and followed up nine months later, of which 19,887 (91\%) were normal weight and 1909 (9\%) were underweight at baseline. Weight and height were objectively measured. Weight perception, weight-change intention, weight control practices, weight-related behaviors, and demographic information were obtained by questionnaires.

Results: Among children with underweight or normal-weight, the cumulative incidence of overweight/obesity was 2.77\% (95\% Cl 2.55-2.99). Among normal-weight children, those who overestimated their weight had higher baseline BMI z-scores and an increased relative risk (RR) of overweight/obesity (RR 1.51,95\% Cl 1.15-1.99). Children who misperceived themselves as underweight or overweight had stronger weight-change intention than their counterparts. However, children with weight-change intention did not develop greater changes in dietary intakes, physical activities, or sedentary behaviors than those without intention. There was no significant association between weight-change intention and incidence after adjusting for BMI z-scores at baseline. Self-reported improving diet, increasing physical activity, and dieting were associated with certain actual behavioral improvements and smaller increase in BMI z-score, but not associated with decreased risk of overweight/obesity.

Conclusion: The 9-months cumulative incidence of overweight/obesity was $2.77 \%$ among Chinese children. Weight-change intention was not associated with incidence of overweight/obesity in normal-weight children, regardless of their weight perception. More importantly, children's weight-change intention was insufficient in achieving desirable behavioral changes. Future overweight and obesity prevention programs should directly target on promoting children's actual behavioral changes.
\end{abstract}

Keywords: Childhood obesity, Incidence, Weight-change intention, Weight-control practices, Behavioral change

\footnotetext{
* Correspondence: majunt@bjmu.edu.cn; jingjin@mail.sysu.edu.cn

${ }^{+} \mathrm{Li}$ Cai and Meixia Dai contributed equally to this work.

${ }^{2}$ School of Public Health, Peking University, Beijing, China

'Department of Maternal and Child Health, School of Public Health, Sun

Yat-Sen University, Guangzhou, China
}

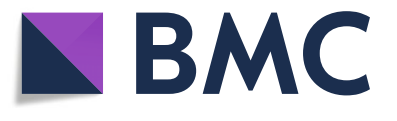

(c) The Author(s). 2018 Open Access This article is distributed under the terms of the Creative Commons Attribution 4.0 International License (http://creativecommons.org/licenses/by/4.0/), which permits unrestricted use, distribution, and reproduction in any medium, provided you give appropriate credit to the original author(s) and the source, provide a link to the Creative Commons license, and indicate if changes were made. The Creative Commons Public Domain Dedication waiver (http://creativecommons.org/publicdomain/zero/1.0/) applies to the data made available in this article, unless otherwise stated. 


\section{Introduction}

The substantial increase in childhood overweight and obesity poses a major public health problem worldwide $[1,2]$. Fueled by the new dietary patterns and sedentary lifestyles, childhood obesity in China also increased rapidly during the past two decades [3]. In 2013, approximately $23.0 \%$ and $14.0 \%$ of Chinese boys and girls aged 2-19 years were overweight or obese [2]. As childhood obesity damages health beginning early in life, it is imperative to take early intervention. Identification of promising intervention strategies requires a clear understanding of modifiable factors contributing to childhood obesity. Specifically, gaps persist in our knowledge about how psychosocial factors impact the development of obesity among children [4].

Weight-change intention is an important psychosocial factor for effective interventions on childhood obesity. It is supposed to mediate the relationship between weight perception and weight-related behaviors, subsequently lead to weight change [5-10]. Generally, children with overweight perception showed stronger intention to lose weight and had higher reporting rates of weight-control behaviors, such as dieting and exercise $[5,6,8]$. Inconsistent to these findings, several prospective studies found that overweight perception was related to larger weight gain and increased risk of overweight and obesity among normal-weight adolescents [11-13]. A suggested explanation for the increased risk was that these adolescents may be more likely to adopt unhealthy weight-control behaviors, resulting in subsequently overweight and obesity [12, 13]. However, children's actual changes in dietary intakes, physical activities and sedentary behaviors were not empirically examined in these studies.

Several additional gaps remain in the existing literature. First, the prevalence of overweight/obesity refers to the proportion of children who are overweight/obesity at a specific period of time, while the incidence of overweight/obesity reflects the frequency of children who become overweight/obesity during a particular time period [14]. Although the prevalence of overweight/obesity in Chinese children has been well investigated, little is known about the incidence [3]. Examining the incidence may provide insights into the development of obesity and inform intervention $[15,16]$. Second, according to the Theory of Planned Behavior, weight related intention (e.g., lose weight) is an important first step for proceeding to behaviors in adults [17-19]; nevertheless, the practical effect of weight-change intention on behavioral changes among normal-weight children remained unclear. What's more, whether weight-change intention was related to a decreased risk of overweight/obesity was seldom investigated.

Thus, we followed up a national sample of Chinese children aged 6-17 years for 9 months to assess whether weight-change intention showed effects on childhood weight status and weight-related behaviors. We were particularly interested in examining the following: (1) national incidence of childhood overweight/obesity among Chinese children; (2) the association between weight-change intention and the incidence of overweight/obesity; and (3) whether changes in dietary intakes, physical activities and sedentary behaviors differed by weight-change intention.

\section{Methods}

\section{Study design and participants}

Data were obtained from a national multi-center random controlled school-based obesity intervention program conducted from September, 2013 to June, 2014 in China (Registration number: NCT02343588). Using multistage cluster sampling method, 94 primary and secondary schools from 7 provinces were selected and randomized into control or intervention group. Study design and sampling procedures were reported in detail elsewhere [20]. In the current study, we only included initial normal-weight $(n=20,141)$ or underweight $(n=1980)$ children from the control group. These children were all enrolled in baseline measurement and $98.5 \%$ of them ( $n=21,796,19,887$ and 1909 of them were normaland underweight respectively) participated the follow-up data collection. The analytic sample consists of the 21,796 children with baseline and follow-up data. All children and their parents signed informed consents and the protocol was approved by the Ethical Committee of the Peking University.

\section{Anthropometric measurement}

\section{$B M I, B M I$ z-scores and weight status}

Weight and height were objectively measured both at baseline and follow-up. Children were required to remove their shoes and socks. Afterwards, their height and weight were measured by qualified technicians in increments of $0.1 \mathrm{~cm}$ and $0.1 \mathrm{~kg}$, respectively, while they were wearing light clothing. Body mass index (BMI) was calculated (weight $(\mathrm{kg}) /$ height $\left(\mathrm{m}^{2}\right)$ ). Sex- and age- specific BMI z-scores were computed using the reference provided by the World Health Organization (WHO) [21]. Weight status was classified as underweight, normal weight, overweight and obesity using the WHO growth reference curves for 6-year-old children, and Chinese criteria [22] for children aged 7-18 years.

\section{Onset of overweight and obesity and incidence}

Binary indicators of incident overweight and obesity were constructed. Change from underweight or normal weight at baseline to overweight (including obesity) at follow-up was coded as incident overweight (obesity). All the participants in this study were normal- or 
underweight at baseline and thus were at risk for incident overweight and obesity. Cumulative incidence was calculated by dividing the number of newly overweight or obese children by the number of children at risk $(n=$ 21,796). While incidence rate was obtained by dividing the number of new overweight or obesity cases by the number of person-years of follow-up, which was expressed as a rate per 1000 person-years.

\section{Questionnaire survey}

The methods used for data collection have been described elsewhere [10]. In brief, well-trained investigators distributed child-reported and parent-reported questionnaires to children in class and interpreted all of the items in child-reported questionnaires in detail. Children were instructed to deliver the questionnaires to their parents. Parents were instructed to fill out the parent-reported questionnaires, assist their children in completing the child-reported questionnaires and return the questionnaires in 3 days. All questionnaires were checked for logicality and integrity upon return. Investigators were trained to verify the illogical answers and obtain answers for the missing items by asking the children or calling their parents.

\section{Demographics information}

Parents' educational level, monthly family income and family location were based on parent report at baseline.

\section{Weight perception}

Weight perception was assessed at baseline by comparing their perceived and actual weight status. Perceived weight was collected by asking children 'How would you describe your weight?' with response options including 'very thin', 'slightly thin,' 'about right,' slightly fat' and 'very fat'. If 'about right' were selected, the normal-weight children were considered as having accurate weight perception; if not, they were considered as having weight misperception, which can be underestimation or overestimation.

\section{Weight-change intention}

Children's weight-change intention was captured at baseline by asking them 'Do you want to change your weight status?' with response options including 'no', 'rather no,' 'not sure', 'rather yes', and 'yes'. The 5-point responses were reclassified as trinary variables (no/not sure/yes).

\section{Weight-control practices}

Weight control practices were binary coded at follow-up. Children reported whether they had used one or more of the following 4 practices to lose weight (yes/no) during the last 3 months: improving diet (e.g. eat more fruit and vegetable, eat less high-energy snacks), increasing physical activity, dieting, or taking weight loss drugs.

\section{Dietary intakes, physical activities and sedentary behaviors}

Dietary intakes were assessed using 8 items. Children reported the frequency (days) and amount (servings) of fruits, vegetables, meat products and sugar-sweetened beverages intakes during the last 7 days. The average daily consumptions of these food intakes were calculated. Children reported amount (servings) of milk products, high-energy snacks, fried food, and Western fast food intake during the last 7 days. Physical activities and sedentary behaviors were assessed by 3 items respectively. Physical activities included vigorous-intensity physical activities (VPA), moderate-intensity physical activities (MPA) and walking. Children reported the frequency (days) and duration (hours and minutes in each of those days) of these activities during the last 7 days. The average daily time of physical activities were calculated. Sedentary behaviors included doing homework, viewing television and using a computer (including playing videogames). Children reported the average amount of time (hours and minutes) they spent daily on the three behaviors during the last 7 days. These variables were assessed both at baseline and follow-up. Changes were calculated as average daily consumption/time at follow-up minus that at baseline. The reliability and validity of the questionnaires of dietary intakes, physical activities and sedentary behaviors were assessed in a sample of 298 children. The results indicate that the questionnaires have acceptable reliability and validity (data not shown).

\section{Statistical analysis}

Descriptive results were expressed as mean [standard deviation (SD)] for continuous variables and frequency for categorical variables. Differences of continuous variables between/among groups were evaluated employing $t$-test or analysis of variance. For categorical variables, chi-square tests were employed. The age-, sex- and baseline BMI z-score controlled effect of weight-change intention/self-reported weight control practices on categorical and continuous outcomes were evaluated by the Cochran-Mantel-Hansel test and general liner model respectively. Logistic regression models were run to estimate the associations between weight-change intention and incidence of childhood overweight/obesity. Sets of variables that might confound the associations were adjusted sequentially. The fully adjusted model included demographics (i.e., age, sex, ethnicity, family income, parents' education level, location and region), children's weight perception and BMI z-score at baseline. Analyses were conducted using SAS version 9.2 (SAS Institute, 
Cary, NC, USA). All tests were 2-sided and considered statistically significant at $P<0.05$.

\section{Results}

The baseline characteristics of the normal-weight children are represented in Table 1. Of the 19,887 children, nearly half were boys (47.1\%). The mean age was 10.84 (SD 3.38) years old. Compared with girls, boys were slightly younger and had higher BMI z-scores at baseline (all $P<0.001$ ). Approximately half of the fathers and mothers had an education level of junior high school or below. The majority of (44.5\%) parents reported their monthly family income were in the range of 200012,000 RMB.

In addition to the overall cumulative incidence and incidence rate of overweight/obesity, we also estimated the age-specific rates of overweight/obesity for age group. As shown Additional file 1, approximately 3.03\% (2.98\% for boys and $3.08 \%$ for girls) of normal-weight children became overweight or obese during the nine-month follow-up, with the age-specific cumulative incidence ranging from 2.47 to $3.78 \%$. An overall incidence rate was 49.23 per 1000 person-years (PY) among them (Fig. 1b). When under-weight children were also included, the cumulative incidence was $2.77 \%$ (2.68\% for boys and $2.85 \%$ for girls), ranging from 2.28 to $3.39 \%$ by age (Additional file 1), and the incidence rate was 44.96 per 1000PY (Fig. 1a).

As listed in Table 2, no sex difference in cumulative incidence of overweight/obesity was observed. The highest incidence of overweight/obesity in boys according to maternal educational levels was among those whose mothers graduated from College or above $(P<0.01)$, while the association was not observed among girls. Higher incidences were observed particularly in Liaoning, Tianjin and Shanghai $(P<0.001)$. Among children with a BMI $z$-score $\geq 0.75$ at baseline, $17.78 \%$ of them ( $15.16 \%$ in boys and $21.5 \%$ in girls) became overweight/ obesity at follow up, whereas only $0.31 \%$ were observed among those who had a baseline BMI z-score below zero.

Overall, $44.40 \%$ of children intended to change weight status at baseline, while the corresponding proportion was much lower in children with accurate weight perception $(31.5 \%)$ than that in underestimation $(50.1 \%)$ or overestimation (83.1\%) group (Table 3). When compared to children with accurate weight perception, though children with overweight perception had smaller increase in BMI $\mathrm{z}$-score $(P<0.001)$, they had higher risk of overweight/obesity after adjusted covariates [relative risk $(\mathrm{RR})=1.51,95 \%$ confidence interval (CI): 1.15, 1.99)]. Surprisingly, children who intended to change weight status showed greater increase in BMI $z$-score at follow-up than those who did not $(P<0.01)$. Children with weight-change intention had higher risk for overweight/obesity ( $R R=1.67,95 \% \mathrm{CI}$ : $1.08,2.59$ ) only in those with accurate weight perception. However, the association became insignificant after adjusting for BMI z-score at baseline and other covariates (Table 3).

The actual changes in dietary intakes (Additional file 2), physical activities and sedentary behaviors (Additional file 3) were largely similar between different intention groups. Children with accurate weight perception and intention to change weight had more decrease in intakes of fried food than those who did not $(P=0.02)$. Among children with overweight perception, those who intended to change weight had greater increase in intakes of fruit $(P=0.02)$ than those who did not.

Table 4 shows that $59.43 \%$ of the children adopted at least one of the four practices to lose weight during the last three months before follow-up. The corresponding proportion was also up to over $50 \%$ in those without weight change intention. Children were more likely to adopt improving diet (45.11\%) and increasing physical activity (49.91\%) than dieting (7.19\%) and taking weight loss drugs (2.28\%).

As shown in Table 5, after adjusting for age, sex and baseline BMI $\mathrm{z}$-score, children who self-reported improving diet, increasing $\mathrm{PA}$, or dieting had smaller increase in BMI $\mathrm{z}$-score $(P<0.05)$. However, their new-onset overweight/obesity was not significantly lower than their counterparts. Indeed, children reported improving dietary had greater increase in intakes of fruit and vegetables, and greater decrease in sugar-sweetened beverages and high-energy snacks consumption when compared with those who did not (Additional file 4). Similarly, children reported increasing physical activity had greater increase in MPA, VPA, MVPA and walking than those who did not (Additional file 5).

\section{Discussion}

This study assessed the incidence of overweight/obesity in a national sample of Chinese children. To our knowledge, this is the first longitudinal study to explore the associations between weight-change intention and incident overweight/obesity in a national sample of children. Misperceiving oneself as underweight or overweight was related to stronger intention to change weight among normal-weight children. Children with weight-change intention were more likely to report weight-control practices as compared with their counterparts, yet they showed little actual improvements in dietary intakes, physical activities or sedentary behaviors. In addition, there were no significant association between weight-change intention and new-onset overweight/ obesity. Self-reported weight-control practices were associated with certain healthy behavioral changes and less 
Table 1 General characteristics of children with normal-weight at baseline by sex

\begin{tabular}{|c|c|c|c|c|}
\hline & Overall & Boys & Girls & $P^{a}$ \\
\hline & 19,887 & $9361(47.1 \%)$ & $10,526(52.9 \%)$ & \\
\hline Age (years) $(\text { mean } \pm S D)^{*}$ & $10.84 \pm 3.38$ & $10.74 \pm 3.36$ & $10.93 \pm 3.39$ & $<0.001$ \\
\hline $6-11.9$ & $11,242(56.5 \%)$ & $5481(58.6 \%)$ & $5761(54.7 \%)$ & \\
\hline $12-18$ & $8645(43.5 \%)$ & $3880(41.5 \%)$ & $4765(45.3 \%)$ & \\
\hline Ethnicity & & & & 0.442 \\
\hline Han & $16,618(94.3 \%)$ & 7755 (94.2\%) & $8863(94.4 \%)$ & \\
\hline Others & $1006(5.7 \%)$ & $482(5.9 \%)$ & $524(5.6 \%)$ & \\
\hline Paternal education level & & & & $<0.001$ \\
\hline Junior high school or below & $7855(47.7 \%)$ & $3748(49.2 \%)$ & $4107(46.3 \%)$ & \\
\hline Senior high school & $4505(27.4 \%)$ & $2065(27.1 \%)$ & $2440(27.5 \%)$ & \\
\hline Junior college & $2127(12.9 \%)$ & 939 (12.3\%) & $1188(13.4 \%)$ & \\
\hline College or above & $1987(12.1 \%)$ & $860(11.3 \%)$ & $1127(12.7 \%)$ & \\
\hline Maternal education level & & & & $<0.001$ \\
\hline Junior high school or below & $8529(51.9 \%)$ & $4061(53.6 \%)$ & $4468(50.5 \%)$ & \\
\hline Senior high school & $4107(25.0 \%)$ & 1849 (24.4\%) & $2258(25.5 \%)$ & \\
\hline Junior college & $2049(12.5 \%)$ & $875(11.6 \%)$ & $1174(13.3 \%)$ & \\
\hline College or above & $1741(10.6 \%)$ & $786(10.4 \%)$ & $955(10.8 \%)$ & \\
\hline Monthly family income & & & & $<0.001$ \\
\hline$<2000$ RMB & $1573(7.9 \%)$ & $702(7.5 \%)$ & $871(8.3 \%)$ & \\
\hline 2000-5000 RMB & $4293(21.6 \%)$ & $1985(21.2 \%)$ & $2308(21.9 \%)$ & \\
\hline $5000-12,000$ RMB & $4560(22.9 \%)$ & $2089(22.3 \%)$ & $2471(23.5 \%)$ & \\
\hline$\geq 12,000 \mathrm{RMB}$ & $1487(7.5 \%)$ & $690(7.4 \%)$ & $797(7.6 \%)$ & \\
\hline Refuse to answer & $7974(40.1 \%)$ & 3895 (41.6\%) & $4079(38.8 \%)$ & \\
\hline Location & & & & 0.410 \\
\hline Urban & $13,111(65.9 \%)$ & $6144(65.6 \%)$ & $6967(66.2 \%)$ & \\
\hline Rural & $6776(34.1 \%)$ & $3217(34.4 \%)$ & $3559(33.8 \%)$ & \\
\hline Region & & & & 0.171 \\
\hline Liaoning & $2870(14.4 \%)$ & $1326(14.2 \%)$ & $1544(14.7 \%)$ & \\
\hline Tianjin & $2819(14.2 \%)$ & $1368(14.6 \%)$ & $1451(13.8 \%)$ & \\
\hline Shanghai & $2849(14.3 \%)$ & $1316(14.1 \%)$ & $1533(14.6 \%)$ & \\
\hline Ningxia & $1993(10.0 \%)$ & $934(10.0 \%)$ & $1059(10.1 \%)$ & \\
\hline Chongqing & $3389(17.0 \%)$ & $1616(17.3 \%)$ & $1773(16.8 \%)$ & \\
\hline Hunan & $3040(15.3 \%)$ & $1467(15.7 \%)$ & $1573(14.9 \%)$ & \\
\hline Guangdong & $2927(14.7 \%)$ & $1334(14.3 \%)$ & $1593(15.1 \%)$ & \\
\hline 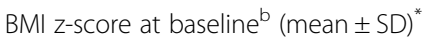 & $-0.17 \pm 0.70$ & $-0.11 \pm 0.71$ & $-0.22 \pm 0.69$ & $<0.001$ \\
\hline$<0$ & $11,442(57.5 \%)$ & 5142 (54.9\%) & $6300(59.9 \%)$ & \\
\hline$\geq 0.00 \sim$ & $2301(11.6 \%)$ & 1051 (11.2\%) & 1250 (11.9\%) & \\
\hline $0.25 \sim$ & $2113(10.6 \%)$ & 996 (10.6\%) & 1117 (10.6\%) & \\
\hline $0.50 \sim$ & 1838 (9.2\%) & 886 (9.5\%) & $952(9.0 \%)$ & \\
\hline$\geq 0.75$ & $2193(11.0 \%)$ & 1286 (13.7\%) & 907 (8.6\%) & \\
\hline
\end{tabular}

aifference between boys and girls; ${ }^{\mathrm{b}} \mathrm{BMI} z$-score was calculated based on the WHO standard; ${ }^{*} P<0.001$. Abbreviations: RMB Renminbi, $B M I$ body mass index, $S D$ standard deviation 

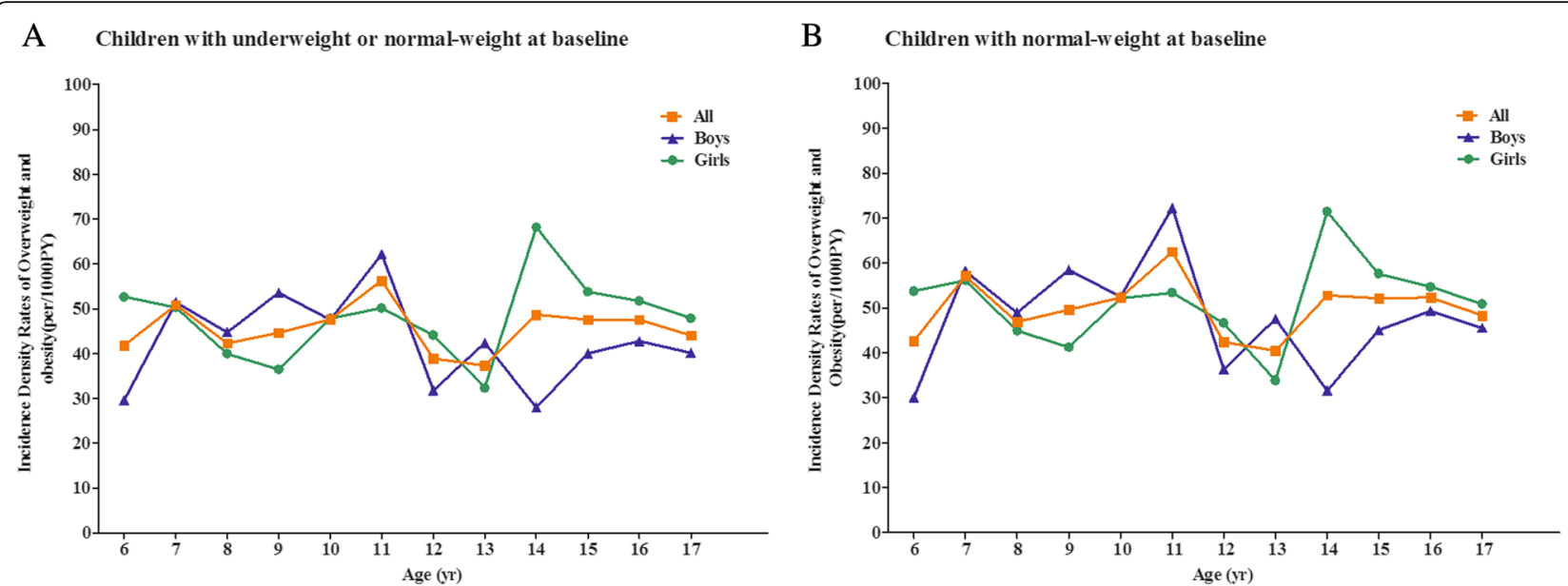

Fig. 1 Incidence density rates of overweight/obesity among children by sex and age. Shown are the incidence density rates according to sex among children with under- or normal-weight (a) and with normal-weight only (b) at baseline

increase in weight gain, but not with incidence of overweight/obesity.

Heretofore, to our knowledge, only 1 study has reported the national incidence of childhood overweight in China [3]. About 5.1\% (approximately 0.57\% annually) and $14.5 \%$ (approximately $1.32 \%$ annually) of children aged 2-18 years became overweight in 1991-2000 and 2000-2011 respectively [3]. In current study, the 9-months cumulative incidence of overweight/obesity among children aged $6-18$ years was $2.77 \%$, which had shown a more than fourfold and twofold increase of the annually incidence observed during 1991-2000 and 2000-2011. This finding was consistent with the substantial increasing prevalence of childhood overweight/ obesity in China $[3,23]$.

The incidence of overweight/obesity in boys and girls were comparable, which was seemingly inconsistent with the sex difference in prevalence of overweight/obesity $[23,24]$. This inconsistency may result from the fact that sex difference in prevalence is already evident at preschool age $[16,25]$. Our data also support this suggestion that $30.4 \%$ of 6 -year-old boys while $16.7 \%$ of 6 -year-old girls were overweight/obese at baseline. The incidence of overweight/obesity was constant across ages. Similar results were obtained from studies in United States showing that the majority of childhood obesity occurred during the preschool years and the incidence declined with age $[16,26]$.

Like previous studies [13, 27], our results demonstrated that initial body weight was a strong predictor of becoming overweight/obesity. Approximately $65 \%$ of the new cases occurred among children with a BMI z-score $\geq 0.75$ at baseline (data not shown). Similarly, about $75 \%$ of American children who became obese between the ages of 5 and 14 years had a BMI z-score above 0.52 at baseline [16]. These findings indicate that overweight and obesity intervention needs to expand the target population to children who are in the range of normal BMI, especially those who are most susceptible to becoming overweight or obesity in less than a year.

Normal-weight children with overweight perception had increased risk of overweight/obesity. This finding is consistent with prior findings $[12,13,28]$. However, we should note that these children actually had less weight gain than their counterparts. They had stronger intention to change weight and were more likely to adopt weight-control practices than those with accurate weight perception, which was in line with previous findings among adolescents and adults [8, 29-32]. However, these children also had a much higher initial BMI z-score. These findings suggest that the increased risk of overweight/obesity in children with overweight perception result from the fact that even a smaller weight gain can make them meet the threshold of overweight/obese. Another noteworthy finding is that the majority of normal weight children adopted weight-control practices, even among those with accurate weight perception. Also, the most frequently adopted practices were both healthy (improving diet and increasing physical activities). Yet, approximately $3.01 \%$ of them failed to maintain healthy weight 9 months later. In fact, nowadays most of children have a good awareness of weight-related knowledge thanks to the public health efforts and the easy access to relevant information $[10,33,34]$. Nevertheless, prevalence of childhood overweight and obesity continues to increase [3]. These results indicate the possibility of a 'ceiling effect' of education about weight perception on childhood obesity prevention. Notably, a total of $2.28 \%$ children with normal weight reported taking weight loss drugs to lose weight during the last three months. The 
Table 2 Cumulative incidence of overweight/obesity among children with normal-weight by sex

\begin{tabular}{|c|c|c|c|c|c|c|}
\hline & All & & Boys & & Girls & \\
\hline & $\%(95 \% \mathrm{Cl})$ & $P$ & $\%(95 \% \mathrm{Cl})$ & $P$ & $\%(95 \% \mathrm{Cl})$ & $P$ \\
\hline & $3.03(2.79,3.27)$ & & $2.98(2.64,3.33)$ & & $3.08(2.75,3.41)$ & \\
\hline Age(years) & & 0.689 & & 0.234 & & 0.706 \\
\hline $6-11.9$ & $3.09(2.77,3.41)$ & & $3.16(2.69,3.62)$ & & $3.02(2.58,3.46)$ & \\
\hline $12-17$ & $2.96(2.60,3.32)$ & & $2.73(2.22,3.25)$ & & $3.15(2.65,3.64)$ & \\
\hline Ethnicity & & 0.644 & & 0.558 & & 0.937 \\
\hline Han & $2.94(2.68,3.19)$ & & $2.95(2.58,3.33)$ & & $2.92(2.57,3.27)$ & \\
\hline Others & $2.68(1.69,3.68)$ & & $2.49(1.10,3.88)$ & & $2.86(1.43,4.29)$ & \\
\hline Paternal education level & & 0.650 & & 0.549 & & 0.109 \\
\hline Junior high school or below & $3.04(2.66,3.42)$ & & $2.80(2.27,3.33)$ & & $3.26(2.72,3.81)$ & \\
\hline Senior high school & $2.77(2.30,3.25)$ & & $3.15(2.39,3.90)$ & & $2.46(1.84,3.07)$ & \\
\hline Junior college & $3.10(2.37,3.84)$ & & $2.77(1.72,3.82)$ & & $3.37(2.34,4.39)$ & \\
\hline College or above & $2.62(1.92,3.32)$ & & $3.26(2.07,4.44)$ & & $2.13(1.29,2.97)$ & \\
\hline Maternal education level & & 0.880 & & 0.008 & & 0.099 \\
\hline Junior high school or below & $2.86(2.51,3.21)$ & & $2.54(2.05,3.02)$ & & $3.16(2.64,3.67)$ & \\
\hline Senior high school & $3.09(2.56,3.62)$ & & $3.14(2.34,3.93)$ & & $3.06(2.35,3.77)$ & \\
\hline Junior college & $3.03(2.28,3.77)$ & & $3.31(2.13,4.50)$ & & $2.81(1.87,3.76)$ & \\
\hline College or above & $2.81(2.04,3.59)$ & & $4.20(2.80,5.60)$ & & $1.68(0.86,2.49)$ & \\
\hline Monthly family income & & 0.083 & & 0.067 & & 0.315 \\
\hline$<2000$ RMB & $2.35(1.60,3.10)$ & & $1.85(0.85,2.85)$ & & $2.76(1.67,3.84)$ & \\
\hline 2000-5000 RMB & $3.10(2.58,3.62)$ & & $3.58(2.76,4.39)$ & & $2.69(2.03,3.35)$ & \\
\hline 5000-12,000 RMB & $3.46(2.93,4.00)$ & & $3.40(2.62,4.18)$ & & $3.52(2.79,4.25)$ & \\
\hline$\geq 12,000 \mathrm{RMB}$ & $2.29(1.53,3.05)$ & & $2.17(1.09,3.26)$ & & $2.38(1.32,3.44)$ & \\
\hline Refuse to answer & $3.02(2.65,3.40)$ & & $2.80(2.28,3.32)$ & & $3.24(2.69,3.78)$ & \\
\hline Location & & 0.573 & & 0.810 & & 0.587 \\
\hline Urban & $3.08(2.79,3.38)$ & & $3.01(2.58,3.44)$ & & $3.14(2.73,3.55)$ & \\
\hline Rural & $2.94(2.53,3.34)$ & & $2.92(2.34,3.50)$ & & $2.95(2.39,3.51)$ & \\
\hline Region & & $<0.001$ & & $<0.001$ & & 0.244 \\
\hline Liaoning & $4.29(3.54,5.03)$ & & $4.98(3.81,6.15)$ & & $3.69(2.75,4.63)$ & \\
\hline Tianjin & $3.19(2.54,3.84)$ & & $2.70(1.84,3.56)$ & & $3.65(2.69,4.62)$ & \\
\hline Shanghai & $3.40(2.74,4.07)$ & & $3.88(2.83,4.92)$ & & $3.00(2.15,3.85)$ & \\
\hline Ningxia & $2.81(2.08,3.54)$ & & $2.46(1.47,3.46)$ & & $3.12(2.07,4.16)$ & \\
\hline Chongqing & $2.74(2.19,3.29)$ & & $2.23(1.51,2.95)$ & & $3.21(2.39,4.04)$ & \\
\hline Hunan & $2.20(1.68,2.73)$ & & $1.77(1.10,2.45)$ & & $2.61(1.82,3.39)$ & \\
\hline Guangdong & $2.63(2.05,3.21)$ & & $3.00(2.08,3.91)$ & & $2.32(1.58,3.06)$ & \\
\hline BMI z-score at baseline ${ }^{a}($ mean $(95 \mathrm{C} \mid \%))$ & & $<0.001$ & & $<0.001$ & & $<0.001$ \\
\hline$<0$ & $0.31(0.20,0.41)$ & & $0.23(0.10,0.37)$ & & $0.37(0.22,0.51)$ & \\
\hline$>0.00 \sim$ & $0.57(0.26,0.87)$ & & $0.67(0.17,1.16)$ & & $0.48(0.10,0.86)$ & \\
\hline $0.25 \sim$ & $2.18(1.55,2.80)$ & & $1.81(0.98,2.63)$ & & $2.51(1.59,3.42)$ & \\
\hline $0.50 \sim$ & $6.47(5.35,7.60)$ & & $5.30(3.83,6.78)$ & & $7.56(5.88,9.24)$ & \\
\hline$\geq 0.75$ & $17.78(16.18,9.38)$ & & $15.16(13.2,17.12)$ & & $21.5(18.83,24.17)$ & \\
\hline
\end{tabular}

${ }^{\mathrm{a} B M I} \mathrm{z}$-score was calculated based on the WHO standard

Abbreviations: $C l$ confidence interval, $R M B$ Renminbi, $B M I$ body mass index 
Table 3 Cumulative incidence of overweight/obesity, and its association with weight-related attitudes

\begin{tabular}{|c|c|c|c|c|c|c|c|}
\hline \multirow[t]{2}{*}{ Weight-related attitudes } & \multirow[t]{2}{*}{$\%$} & \multirow{2}{*}{$\begin{array}{l}\text { BMI z-score } \\
\text { at baseline }\end{array}$} & \multirow{2}{*}{$\begin{array}{l}\text { Changes in } \\
\text { BMl z-score }\end{array}$} & \multirow{2}{*}{$\begin{array}{l}\text { Cumulative Incidence } \\
\%(95 \% \mathrm{Cl})\end{array}$} & \multicolumn{3}{|l|}{ RR $(95 \%$ Cl) } \\
\hline & & & & & Model $1^{d}$ & Model $2^{e}$ & Model $3^{f}$ \\
\hline \multicolumn{8}{|l|}{ All children } \\
\hline \multicolumn{8}{|l|}{ Self-weight perception } \\
\hline Underestimation & 34.28 & $-0.59 \pm 0.61^{b}$ & $0.12 \pm 0.41^{c}$ & $0.65(0.45,0.86)$ & $0.19(0.13,0.27)$ & $0.88(0.61,1.28)$ & $0.71(0.45,1.12)$ \\
\hline Accurate estimation & 52.98 & $-0.01 \pm 0.64$ & $0.11 \pm 0.39$ & $3.01(2.66,3.35)$ & 1.00 & 1.00 & 1.00 \\
\hline Overestimation & 12.74 & $0.35 \pm 0.56$ & $0.07 \pm 0.36$ & $8.67(7.50,9.84)$ & $3.19(2.55,3.98)$ & $1.49(1.18,1.89)$ & $1.51(1.15,1.99)$ \\
\hline \multicolumn{8}{|c|}{ Willingness to change weight status } \\
\hline Yes & 44.40 & $-0.15 \pm 0.73^{b}$ & $0.11 \pm 0.40$ & $3.65(3.24,4.07)$ & $1.59(1.12,2.26)$ & $1.16(0.80,1.68)$ & $1.14(0.78,1.66)$ \\
\hline Not sure & 11.00 & $-0.14 \pm 0.68$ & $0.11 \pm 0.39$ & $2.03(1.40,2.66)$ & 1.00 & 1.00 & 1.00 \\
\hline No & 44.50 & $-0.18 \pm 0.68$ & $0.09 \pm 0.39$ & $2.42(2.08,2.76)$ & $1.25(0.88,1.77)$ & $1.36(0.94,1.97)$ & $1.35(0.93,1.96)$ \\
\hline \multicolumn{8}{|l|}{ Underestimation } \\
\hline \multicolumn{8}{|c|}{ Willingness to change weight status ${ }^{a}$} \\
\hline Yes & 50.10 & $-0.64 \pm 0.60^{b}$ & $0.10 \pm 0.40^{c}$ & $0.50(0.25,0.76)$ & $0.65(0.24,1.81)$ & $0.74(0.26,2.13)$ & $0.77(0.25,2.35)$ \\
\hline Not sure & 10.80 & $-0.56 \pm 0.61$ & $0.13 \pm 0.41$ & $0.78(0.10,1.46)$ & 1.00 & 1.00 & 1.00 \\
\hline No & 39.10 & $-0.55 \pm 0.61$ & $0.13 \pm 0.42$ & $0.81(0.45,1.18)$ & $1.23(0.45,3.32)$ & $0.99(0.35,2.78)$ & $1.07(0.36,3.18)$ \\
\hline \multicolumn{8}{|l|}{ Accurate estimation } \\
\hline \multicolumn{8}{|c|}{ Willingness to change weight status } \\
\hline Yes & 31.50 & $0.03 \pm 0.63^{b}$ & $0.12 \pm 0.41^{c}$ & $3.34(2.69,4.00)$ & $1.67(1.08,2.59)$ & $1.16(0.73,1.84)$ & $1.13(0.71,1.81)$ \\
\hline Not sure & 12.40 & $0.04 \pm 0.61$ & $0.11 \pm 0.39$ & $2.37(1.49,3.25)$ & 1.00 & 1.00 & 1.00 \\
\hline No & 56.10 & $-0.04 \pm 0.65$ & $0.08 \pm 0.37$ & $2.96(2.50,3.42)$ & $1.24(0.82,1.88)$ & $1.40(0.90,2.16)$ & $1.38(0.89,2.15)$ \\
\hline \multicolumn{8}{|l|}{ Overestimation } \\
\hline \multicolumn{8}{|c|}{ Willingness to change weight status } \\
\hline Yes & 83.10 & $0.36 \pm 0.55^{b}$ & $0.10 \pm 0.37$ & $9.18(7.86,10.50)$ & $1.94(0.89,4.24)$ & $1.34(0.59,3.07)$ & $1.27(0.54,2.95)$ \\
\hline Not sure & 6.00 & $0.34 \pm 0.57$ & $0.08 \pm 0.34$ & $5.26(1.47,9.06)$ & 1.00 & 1.00 & 1.00 \\
\hline No & 10.90 & $0.29 \pm 0.57$ & $0.07 \pm 0.35$ & $6.64(3.49,9.78)$ & $1.27(0.51,3.18)$ & $1.29(0.49,3.43)$ & $1.23(0.45,3.34)$ \\
\hline
\end{tabular}

Numbers in bold indicate statistically significant associations

"BMI Z-score was calculated based on the WHO standard; ${ }^{\text {a }}$ Significant difference of weight-change intentions among children with different weight perceptions, $P$ $<0.001{ }^{b}$ Significant difference among children with different weight-perception or weight-change intentions after adjusting for age and sex, $P<0.001 ;{ }^{c}$

Significant difference among children with different weight perceptions or weight-change intentions after adjusting for age, sex and BMI $z$-score at baseline, $P<$ $0.001 ;{ }^{d}$ Adjusted for age, sex and self-perception of weight status (all children only); ${ }^{\mathrm{e}}$ Adjusted for age, sex, BMI z-score and self-perception of weight status (all children only) ${ }^{f}$ Adjusted for age, sex, BMI z-score, income, paternal education level, maternal education level, ethnicity, location and region and self-perception of weight status (all children only)

Abbreviations: $B M I$ body mass index, $\mathrm{Cl}$ confidence interval, $R R$ relative risk

use of weight loss drugs were also reported by children without weight-change intention (2.04\%). Future research is needed to explore and identify risk factors for using weight loss drugs in normal weight children, such as the product accessibility and the influence of parents, peers and the media. In addition, public efforts are needed to strengthen health education for children's use of weight-loss drugs and to strengthen government regulation of weight-loss drugs.

Children's weight-change intention was not significantly associated with incidence of overweight/obesity after adjusting for initial body weight, regardless of their weight perception. These findings were partly consistent with prior results among adults that weight-loss intention was not associated with actual weight loss [35]. Our data also showed that one third of children with weight-change intention did not adopt weight-control practices, while over half of the children without weight-change intention did. Thus, the insignificant associations may due to that children did not necessarily act on their intentions and that those who intended to change weight initiated the actions but failed to maintain them. Another explanation for the insignificant associations is that children' behavioral changes may be too small to reverse the development of overweigh/obesity. Our results showed that children with weight-change intention generally had no more improvements in dietary intakes, physical activities or sedentary behaviors compared with their counterparts without an intention. Discrepancy between weight-loss intention and eating and exercise habits have been reported in youths and adults $[8,36,37]$. Our results added evidences on these 
Table 4 Self-reported weight control practices among children by weight-related attitudes

\begin{tabular}{|c|c|c|c|c|c|}
\hline \multirow{2}{*}{$\begin{array}{l}\text { Weight-related } \\
\text { attitudes }\end{array}$} & Weight-control practice ${ }^{a}$ & improving diet & increasing physical activity & dieting & taking weight loss drugs \\
\hline & $\%(95 \% \mathrm{Cl})$ & $\%(95 \% \mathrm{Cl})$ & $\%(95 \% \mathrm{Cl})$ & $\%(95 \% \mathrm{Cl})$ & $\%(95 \% \mathrm{Cl})$ \\
\hline All children & $59.43(58.71,60.17)$ & $45.11(44.37,45.85)$ & $49.91(49.17,50.65)$ & $7.19(6.81,7.57)$ & $2.28(2.06,2.50)$ \\
\hline \multicolumn{6}{|c|}{ Willingness to change weight status } \\
\hline Yes & $65.73(64.61,66.85)$ & $50.59(49.41,51.76)$ & $54.40(53.23,55.57)$ & $9.39(8.70,10.08)$ & $2.28(1.93,2.63)$ \\
\hline Not sure & $58.71(56.39,61.04)$ & $43.80(41.47,46.14)$ & $49.88(47.53,52.24)$ & $6.73(5.55,7.91)$ & $2.61(1.86,3.36)$ \\
\hline No & $53.58(52.41,54.75)$ & $39.85(38.70,41.00)$ & $46.11(44.94,47.28)$ & $4.69(4.19,5.18)$ & $2.04(1.71,2.37)$ \\
\hline$p^{b}$ & $<0.001$ & $<0.001$ & $<0.001$ & $<0.001$ & 0.277 \\
\hline Underestimate & $49.93(48.58,51.27)$ & $36.17(34.89,37.46)$ & $43.20(41.88,44.53)$ & $5.09(4.50,5.67)$ & $1.98(1.61,2.36)$ \\
\hline \multicolumn{6}{|c|}{ Willingness to change weight status } \\
\hline Yes & $49.70(47.79,51.60)$ & $35.99(34.18,37.81)$ & $43.13(41.26,45.01)$ & $4.96(4.14,5.79)$ & $1.92(1.40,2.44)$ \\
\hline Not sure & $50.61(46.51,54.72)$ & $38.50(34.52,42.48)$ & $42.51(38.46,46.55)$ & $7.52(5.36,9.68)$ & $2.80(1.45,4.16)$ \\
\hline No & $50.00(47.86,52.14)$ & $35.83(33.78,37.88)$ & $43.47(41.35,45.58)$ & $4.53(3.64,5.42)$ & $1.86(1.28,2.43)$ \\
\hline$p^{b}$ & 0.499 & 0.447 & 0.599 & 0.513 & 0.894 \\
\hline Accurate estimate & $61.43(60.38,62.48)$ & $46.86(45.79,47.93)$ & $52.22(51.15,53.29)$ & $6.46(5.93,6.99)$ & $2.19(1.88,2.51)$ \\
\hline \multicolumn{6}{|c|}{ Willingness to change weight status } \\
\hline Yes & $72.54(70.84,74.25)$ & $56.71(54.83,58.60)$ & $60.60(58.74,62.46)$ & $9.88(8.74,11.02)$ & $2.24(1.68,2.81)$ \\
\hline Not sure & $62.45(59.48,65.42)$ & $46.84(43.79,49.89)$ & $53.40(50.35,56.45)$ & $6.08(4.61,7.55)$ & $2.74(1.74,3.74)$ \\
\hline No & $54.84(53.41,56.28)$ & $41.21(39.80,42.62)$ & $47.17(45.74,48.60)$ & $4.58(3.98,5.18)$ & $2.03(1.62,2.44)$ \\
\hline$p^{\mathrm{b}}$ & $<0.001$ & $<0.001$ & $<0.001$ & $<0.001$ & 0.209 \\
\hline Overestimate & $77.81(75.98,79.64)$ & $61.56(59.43,63.69)$ & $60.83(58.69,62.98)$ & $14.38(12.84,15.92)$ & $2.88(2.14,3.62)$ \\
\hline \multicolumn{6}{|c|}{ Willingness to change weight status } \\
\hline Yes & $80.86(78.95,82.78)$ & $64.60(62.28,66.91)$ & $62.71(60.36,65.05)$ & $15.77(14.00,17.54)$ & $2.89(2.07,3.70)$ \\
\hline Not sure & $65.08(56.75,73.41)$ & $42.52(33.91,51.13)$ & $55.91(47.26,64.55)$ & $7.87(3.19,12.56)$ & $0.79(0.00,2.34)$ \\
\hline No & $61.68(55.16,68.20)$ & $49.54(42.90,56.18)$ & $48.85(42.19,55.50)$ & $8.29(4.62,11.97)$ & $4.19(1.51,6.87)$ \\
\hline$p^{b}$ & $<0.001$ & $<0.001$ & $<0.001$ & 0.023 & 0.596 \\
\hline
\end{tabular}

Numbers in bold indicate statistically significant differences with $P$ values

a Self-reported at least one of the four weight control practices; ${ }^{\text {b }}$ Adjusted for age and sex; similar result were obtained when additional adjusted for BMI z-score at baseline

studies and empirically demonstrated that there was a gap between children's weight-change intention and actual behavioral changes.

Both individual and environmental factors could contribute to the gap. The dietary and activity patterns could be effortful to change, considering that they are regulated by intrinsic biological processes [38-40]. In particular, children have strong biological vulnerability to palatable but mostly calorie-dense foods [38, 41]. Besides, Chinese children are now exposed to the so-called "obesogenic environment", which filled with energy-dense foods [33, 42] and emphasized driving over bicycling or walking [24, 43]. Their abilities to adopt and maintain healthy lifestyles can be undermined by current environmental factors [38, 44]. In fact, even among children with overweight perception, who showed the strongest intention to change weight status, only small behavioral improvements in fruit intake and VPA time were observed in those who intended to change weight. Accordingly, facilitating environmental changes may help reduce the amount of willpower necessary to achieve desirable lifestyles $[45,46]$ and should be effective for childhood obesity prevention.

Our study also provides support for the benefit of environmental/physical changes in obesity prevention. We found that weight-control practices did have favorable influence on children's weight. Children who self-reported weight -control practices (e.g., improving diet and increasing physical activity) gained less weight than those who did not, resulting from the fact that they indeed had made slight to moderate improvement in relevant healthy behaviors. However, these children did not have decreased risk of overweight/obesity. These results revealed that though changing diet and lifestyles rely on children alone are of value for weight control, their achievable magnitude of behavioral change couldn't reached the threshold needed to reverse the trend of new onset of overweight/obesity [1].

Findings from our study point out that childhood obesity prevention should directly target on promoting 
Table 5 Changes in BMI z-score and cumulative incidence of overweight/obesity among children by self-reported weight control practices

\begin{tabular}{|c|c|c|c|c|c|c|c|}
\hline \multirow{2}{*}{$\begin{array}{l}\text { Self-reported weight } \\
\text { control practice in } \\
\text { past three months }\end{array}$} & \multicolumn{4}{|c|}{ Changes in BMl z-score ${ }^{*}$} & \multirow{2}{*}{$\begin{array}{l}\text { Cumulative incidence } \\
\%(95 \% \mathrm{Cl})\end{array}$} & \multicolumn{2}{|l|}{ RR $(95 \% \mathrm{Cl})$} \\
\hline & mean $\pm S D$ & $P$ & $p^{b}$ & $p^{c}$ & & Model $1^{b}$ & Model $2^{c}$ \\
\hline Weight-control practice $^{a}$ & & $<0.001$ & 0.015 & $<0.001$ & & & \\
\hline Yes & $0.09 \pm 0.40$ & & & & $3.77(3.40,4.14)$ & $2.14(1.75,2.63)$ & $1.03(0.83,1.29)$ \\
\hline No & $0.11 \pm 0.41$ & & & & $1.80(1.49,2.11)$ & 1.00 & 1.00 \\
\hline Improving diet & & 0.002 & 0.317 & $<0.001$ & & & \\
\hline Yes & $0.09 \pm 0.39$ & & & & $3.83(3.40,4.25)$ & $1.68(1.41,2.01)$ & $0.98(0.81,1.19)$ \\
\hline No & $0.10 \pm 0.41$ & & & & $2.31(2.01,2.61)$ & 1.00 & 1.00 \\
\hline Increasing physical activity & & 0.015 & 0.018 & $<0.001$ & & & \\
\hline Yes & $0.09 \pm 0.39$ & & & & $3.76(3.36,4.16)$ & $1.72(1.44,2.06)$ & $1.00(0.83,1.22)$ \\
\hline No & $0.10 \pm 0.41$ & & & & $2.22(1.91,2.53)$ & 1.00 & 1.00 \\
\hline Dieting & & $<0.001$ & 0.240 & 0.028 & & & \\
\hline Yes & $0.06 \pm 0.39$ & & & & $3.99(2.91,5.08)$ & $1.39(1.03,1.87)$ & $1.16(0.84,1.61)$ \\
\hline No & $0.10 \pm 0.40$ & & & & $2.89(2.63,3.15)$ & 1.00 & 1.00 \\
\hline Taking weight loss drugs & & 0.547 & 0.606 & 0.657 & & & \\
\hline Yes & $0.11 \pm 0.40$ & & & & $2.77(1.16,4.39)$ & $0.93(0.51,1.70)$ & $0.95(0.50,1.82)$ \\
\hline No & $0.10 \pm 0.40$ & & & & $2.98(2.72,3.23)$ & 1.00 & 1.00 \\
\hline
\end{tabular}

Numbers in bold indicate statistically significant differences or associations

${ }^{*} \mathrm{BMI}$ z-score was calculated based on the WHO standard; ${ }^{\text {a }}$ Self-reported at least one of the four weight control practices; ${ }^{\mathrm{b}}$ Adjusted for age and sex; ${ }^{\mathrm{c}}$ Adjusted for age, sex and BMI z-score at baseline

Abbreviations: $B M I$ body mass index, $S D$ standard deviation, $C l$ confidence interval, $R R$ relative risk

children's actual behavioral changes. Although children's subjective weight-change intention shows some impact on their weight-control practices, they are susceptible to failures in achieving desirable healthy lifestyles and healthy weight status if we relied solely on their individual willpower [45]. Therefore, other than general promotions and interventions on children's weight perception and weight control intention-enhancement, obesity prevention program needs to target at providing greater access to healthy food and to places for physical activity in multiple settings [47], from home to school to communities, making it easier for children to achieve desirable healthy lifestyles and healthy weight status.

Strengths of this study include the large sample size, the objectively measured weight and height and the empirical investigation of actual behavioral changes. Therefore, our study could not only reveal but also provide insight to the association between weight-change intention and the risk of overweight/obesity. This study also has several limitations. First, because the Chinese criteria are only applicable to children at age of 718 years and the WHO criteria are recommended for 6-year-old children in China [22, 48], we defined weight status using Chinese criteria for 7-18-year-old children and WHO criteria for 6-year-old children in this study. Using two different sets of criteria may cause potential bias on the convergence of the research results to all participants. However, similar results were obtained when the WHO criteria were applied for the whole sample, indicating the reliability of our results (data not shown). Second, data on behaviors were based on self-reported, which could have led to under- or over-reporting $[49,50]$. However, this under- or over-reporting should have been consistent at baseline and at follow-up, making it unlikely to significantly influence the results. Third, the follow-up period of 9 months may not be long enough for estimating incidence of overweight/obesity accurately. However, these results are still valuable for understanding the current extent of childhood obesity epidemic in China. Further long-term longitudinal studies are warranted to monitor the trend and provide more insights to the nature of the epidemic. Finally, though we had adjusted for important demographic characteristic, we could not completely rule out residual confounding by unmeasured potential confounders.

\section{Conclusion}

The 9-months cumulative incidence of overweight/obesity was $2.77 \%$ among Chinese children. Normal-weight children with overweight perception did not have larger weight gain but had higher risk of overweight/obesity. Children who misperceived themselves as underweight or overweight had stronger intention to change weight. However, weight-change intention was not associated with incidence of overweight/obesity among normal-weight 
children, regardless of their weight perception. Moreover, children's weight-change intention was insufficient in achieving desirable behavioral changes and maintaining healthy weight status. Future overweight and obesity prevention programs should directly target on promoting children's actual behavioral changes, providing permissive and supportive environment to facilitate them achieving healthy lifestyles.

\section{Additional files}

Additional file 1: Cumulative incidence of overweight and obesity among children by sex and age. (DOCX $34 \mathrm{~kb}$ )

Additional file 2: Changes in dietary intakes among children by weightrelated attitudes. (DOCX $34 \mathrm{~kb}$ )

Additional file 3: Changes in physical activities and sedentary behaviors among children by weight-related attitudes. (DOCX 34 kb)

Additional file 4: Self-reported weight control practice and changes in dietary intakes. (DOCX 25 kb)

Additional file 5: Self-reported weight control practice and changes in physical activities and sedentary behaviors. (DOCX $25 \mathrm{~kb}$ )

\section{Abbreviations}

Cl: Confidence interval; MPA: Moderate-intensity physical activities; MVPA: Moderate- or vigorous-intensity physical activities; RR: Relative risk; SD: Standard deviation; VPA: Vigorous-intensity physical activities

\section{Acknowledgements}

We thank all the participating children and their families. We acknowledge the the staffs of the local Education Bureau, the participating principals, teachers, school doctors, and postgraduate for their great contributions to the success of the program.

\section{Funding}

This study was funded by the Research Special Fund for Public Welfare of Health from the Ministry of Health, the People's Republic of China (No. 201202010).

\section{Availability of data and materials}

The data used during the current study cannot be made publicly available. The ethics approval granted for this research do not include consent for the sharing of the datasets that support the analyses and conclusions contained within this article.

\section{Authors' contributions}

$J J$, YJC and JM designed and managed the investigation. MXD, LZL and WHY contributed to the data collection. MXD performed the statistical analysis and drafted the manuscript. LC designed the current study, guided the statistical analysis and critically revised the manuscript. JJ supervised the analysis and revised the manuscript. All authors read and approved the final manuscript.

\section{Ethics approval and consent to participate}

This study was approved by the Ethical Committee of the Peking University. Informed consent was obtained from all individual participants included in the present study.

\section{Consent for publication}

Not applicable.

\section{Competing interests}

The authors declare that they have no competing interests.

\section{Publisher's Note}

Springer Nature remains neutral with regard to jurisdictional claims in published maps and institutional affiliations.

Received: 13 June 2018 Accepted: 16 October 2018

Published online: 03 November 2018

\section{References}

1. Lobstein T, Jackson-Leach R, Moodie ML, Hall KD, Gortmaker SL, Swinburn $\mathrm{BA}$, et al. Child and adolescent obesity: part of a bigger picture. Lancet. 2015:385:2510-20.

2. Ng M, Fleming T, Robinson M, Thomson B, Graetz N, Margono C, et al. Global, regional, and national prevalence of overweight and obesity in children and adults during 1980-2013: a systematic analysis for the global burden of disease study 2013. Lancet. 2014;384:766-81.

3. Gordon-Larsen P, Wang H, Popkin BM. Overweight dynamics in Chinese children and adults. Obes Rev. 2014;15:37-48.

4. Haynes A, Kersbergen I, Sutin A, Daly M, Robinson E. A systematic review of the relationship between weight status perceptions and weight loss attempts, strategies, behaviours and outcomes. Obes Rev. 2018;19:347-63.

5. Quick V, Nansel TR, Liu D, Lipsky LM, Due P, lannotti RJ. Body size perception and weight control in youth: 9-year international trends from 24 countries. Int J Obesity. 2014;38:988-94.

6. Chung $A E$, Perrin EM, Skinner AC. Accuracy of child and adolescent weight perceptions and their relationships to dieting and exercise behaviors: a NHANES study. Acad Pediatr. 2013;13:371-8.

7. Zhao M, Zhang M, Zhou X, Yang H, Yang Y. Weight misperception and its barriers to keep health weight in Chinese children. Acta Paediatr. 2012;101: e550-6.

8. Fan $M$, Jin $Y$. The effects of weight perception on adolescents' weight-loss intentions and behaviors: evidence from the youth risk behavior surveillance survey. Int J Env Res Pub He. 2015;12:14640-68.

9. Swaminathan S, Selvam S, Pauline M, Vaz M. Associations between body weight perception and weight control behaviour in south Indian children: a cross-sectional study. BMJ Open. 2013;3.

10. Cai L, Zhang T, Ma J, Ma L, Jing J, Chen Y. Self-perception of weight status and its association with weight-related knowledge, attitudes, and behaviors among Chinese children in Guangzhou. J Epidemiol. 2017;27:338-45.

11. Cuypers K, Kvaløy K, Bratberg G, Midthjell K, Holmen J, Holmen TL. Being Normal weight but feeling overweight in adolescence may affect weight development into young adulthood - an 11-year Followup: the HUNT study. Norway Journal of Obesity. 2012;2012:1-8.

12. Sutin AR, Terracciano A. Body weight misperception in adolescence and incident obesity in young adulthood. Psychol Sci. 2015;26:507-11.

13. Liechty JM, Lee MJ. Body size estimation and other psychosocial risk factors for obesity onset among US adolescents: findings from a longitudinal population level study. Int J Obes. 2015;39:601-7.

14. Essential epidemiology: an introduction for students and health professionals: Cambridge University Press; 2016.

15. Munn Z, Moola S, Lisy K, Riitano D, Tufanaru C. Methodological guidance for systematic reviews of observational epidemiological studies reporting prevalence and cumulative incidence data. Int J Evid Based Healthc. 2015; 13:147-53.

16. Cunningham SA, Kramer MR, Narayan KMV. Incidence of childhood obesity in the United States. New Engl J Med. 2014;370:403-11.

17. van Genugten $L$, van Empelen P, Oenema A. From weight management goals to action planning: identification of a logical sequence from goals to actions and underlying determinants. J Hum Nutr Diet. 2012;25:354-64.

18. Montano DE, Kasprzyk D. Theory of reasoned action, theory of planned behavior, and the integrated behavioral model. In: Glanz K, Rimer BK, Viswanath K, editors. Health behavior: theory, research and practice. San Francisco, USA: John Wiley \& Sons; 2015. p. 67-96.

19. Schifter DE, Ajzen I. Intention, perceived control, and weight loss: an application of the theory of planned behavior. J Pers Soc Psychol. 1985;49: 843-51.

20. Chen Y, Ma L, Ma Y, Wang H, Luo J, Zhang X, et al. A national school-based health lifestyles interventions among Chinese children and adolescents against obesity: rationale, design and methodology of a randomized controlled trial in China. BMC Public Health. 2015;15:210.

21. de Onis M. Development of a WHO growth reference for school-aged children and adolescents. B World Health Organ. 2007;85:660-7. 
22. Ji CY, Sun JL. Body mass index reference norm for screening overweight and obesity in Chinese children and adolescents. Zhonghua Er Ke Za Zhi. 2004:42:328-32

23. Ji CY, Chen TJ. Empirical changes in the prevalence of overweight and obesity among Chinese students from 1985 to 2010 and corresponding preventive strategies. Biomed Environ Sci. 2013;26:1-12.

24. Cheng TO. China's epidemic of child obesity: an ounce of prevention is better than a pound of treatment. Int J Cardiol. 2014;172:1-7.

25. Zhang T, Cai L, Ma L, Jing J, Chen Y, Ma J. The prevalence of obesity and influence of early life and behavioral factors on obesity in Chinese children in Guangzhou. BMC Public Health. 2016;16:954.

26. Cheung PC, Cunningham SA, Naryan KMV, Kramer MR. Childhood obesity incidence in the United States: a systematic review. Child Obes. 2016;12:1-11.

27. Fredrickson J, Kremer P, Swinburn B, de Silva-Sanigorski A, McCabe M. Biopsychosocial correlates of weight status perception in Australian adolescents. Body Image. 2013:10:552-7.

28. Shirasawa T, Ochiai H, Nanri H, Nishimura R, Ikeda K, Hoshino H, et al. Association between distorted body image and changes in weight status among normal weight preadolescents in Japan: a population-based cohort study. Arch Public Health. 2016;74:39.

29. Fredrickson J, Kremer P, Swinburn B, de Silva A, McCabe M. Weight perception in overweight adolescents: associations with body change intentions, diet and physical activity. J Health Psychol. 2015;20:774-84.

30. Patte KA, Laxer R, Qian W, Leatherdale ST. Weight perception and weightcontrol intention among youth in the COMPASS study. Am J Health Behav. 2016:40:614-23.

31. Tanenbaum HC, Felicitas JQ, Li Y, Tobias M, Chou C, Palmer PH, et al. Overweight perception: associations with weight control goals, attempts, and practices among Chinese female college students. J Acad Nutr Diet. 2016;116:458-66.

32. Duncan DT, Wolin KY, Scharoun-Lee M, Ding EL, Warner ET, Bennett GG. Does perception equal reality? Weight misperception in relation to weightrelated attitudes and behaviors among overweight and obese US adults Int J Behav Nutr Phys Act. 2011;8:20.

33. Wang $H$, Zhai F. Programme and policy options for preventing obesity in China. Obes Rev. 2013;14:134-40.

34. Huang $\mathrm{C}, \mathrm{Yu}$ H, Koplan JP. Can China diminish its burden of noncommunicable diseases and injuries by promoting health in its policies, practices, and incentives? Lancet. 2014;384:783-92.

35. Lee JS, Kritchevsky SB, Tylavsky FA, Harris T, Everhart J, Simonsick EM, et al. Weight-loss intention in the well-functioning, community-dwelling elderly: associations with diet quality, physical activity, and weight change. Am J Clin Nutr. 2004:80:466-74.

36. DiBonaventura MD, Chapman GB. The effect of barrier underestimation on weight management and exercise change. Psychology, Health \& Medicine. 2008:13:111-22

37. Poobalan AS, Aucott LS, Clarke A, Smith WC. Physical activity attitudes, intentions and behaviour among 18-25 year olds: a mixed method study. BMC Public Health. 2012;12:640

38. Roberto CA, Swinburn B, Hawkes C, Huang T, Costa SA, Ashe M, et al. Patchy progress on obesity prevention: emerging examples, entrenched barriers, and new thinking. Lancet. 2015:385:2400-9.

39. Bauman AE, Reis RS, Sallis JF, Wells JC, Loos RJ, Martin BW. Correlates of physical activity: why are some people physically active and others not? Lancet. 2012;380:258-71.

40. Franks PW, Ravussin E, Hanson RL, Harper IT, Allison DB, Knowler WC, et al. Habitual physical activity in children: the role of genes and the environment. Am J Clin Nutr. 2005;82:901-8.

41. Desor JA, Beauchamp GK. Longitudinal changes in sweet preferences in humans. Physiol Behav. 1987:39:639-41.

42. Zhai FY, Du SF, Wang ZH, Zhang JG, Du WW, Popkin BM. Dynamics of the Chinese diet and the role of urbanicity, 1991-2011. Obes Rev. 2014;15:16-26.

43. Day K, Alfonzo M, Chen Y, Guo Z, Lee KK. Overweight, obesity, and inactivity and urban design in rapidly growing Chinese cities. Health Place. 2013;21: 29-38.

44. Stankov I, Olds T, Cargo M. Overweight and obese adolescents: what turns them off physical activity? Int J Behav Nutr Phys Act. 2012;9:53.

45. Mann T, Tomiyama AJ, Ward A. Promoting public health in the context of the "obesity epidemic": false starts and promising new directions. Perspect Psychol Sci. 2015;10:706-10.
46. Wang Y, Cai L, Wu Y, Wilson RF, Weston C, Fawole O, et al. What childhood obesity prevention programmes work? A systematic review and metaanalysis. Obes Rev. 2015;16:547-65.

47. Mayne SL, Auchincloss AH, Michael YL. Impact of policy and built environment changes on obesity-related outcomes: a systematic review of naturally occurring experiments. Obes Rev. 2015;16:362-75.

48. Maternal and Child Health Branch of Chinese Nutrition Society. Nutrition and food guidelines for women in pregnancy and lactation, and children from 0 to 6 years of China [in Chinese]. Beijing: People's Medical Publishing House; 2007.

49. Adamo KB, Prince SA, Tricco AC, Connor-Gorber S, Tremblay M. A comparison of indirect versus direct measures for assessing physical activity in the pediatric population: a systematic review. Int J Pediatr Obes. 2009;4: 2-27.

50. Burrows TL, Martin RJ, Collins CE. A systematic review of the validity of dietary assessment methods in children when compared with the method of doubly labeled water. J Am Diet Assoc. 2010;110:1501-10.

\section{Ready to submit your research? Choose BMC and benefit from:}

- fast, convenient online submission

- thorough peer review by experienced researchers in your field

- rapid publication on acceptance

- support for research data, including large and complex data types

- gold Open Access which fosters wider collaboration and increased citations

- maximum visibility for your research: over $100 \mathrm{M}$ website views per year

At BMC, research is always in progress.

Learn more biomedcentral.com/submissions 